\title{
First record of Monacha (Monacha) obstructa (L. Pfeiffer, 1842) and Polygyra cereolus (Megerle von Mühlfeldt, 1818) (Stylommatophora Hygromiidae and Polygyridae) in Libya
}

\author{
Fabio Liberto', Abdelmuhsen Abusneina² \& Ignazio Sparacio ${ }^{3}$ \\ ${ }^{1}$ Via del Giubileo Magno 93, 90015 Cefalù, Italy; e-mail: fabioliberto@yahoo.it \\ ${ }^{2}$ Department of Zoology, Faculty of Science, University of Benghazi, Benghazi, Libya; e-mail: abdelmuhsen. \\ abusneina@uob.edu.ly \\ ${ }^{3}$ Via Principe di Paternò 3, 90144 Palermo, Italy; e-mail: edizionidanaus@gmail.com
}

\begin{abstract}
The present contribution outlines a first record of two allochthonous land snails Monacha obstructa (L. Pfeiffer, 1842) and Polygyra cereolus (Megerle von Mühlgeldt, 1818) in Cyrenaica (Northeast Libya) (Stylommatophora Hygromiidae and Polygyridae). The two species have been identified through the study of the shell and the genitalia. Their zoogeographical origins, the possible way of introduction and distribution in Libya are discussed.
\end{abstract}

KEY WORDS Land snail; new record; allochthonous species; morphology.

Received 03.03.2021; accepted 28.04.2021; published online 30.06.2021

\section{INTRODUCTION}

Libya's non-marine molluscs were intensively studied between the 1920s and 1960s, mainly thanks to research carried out by the malacologists Laura Gambetta (1901-19**), Herbert Kaltenback (18891963) and Rolf Brandt (1917-1989).

Recent collections have made it possible to record some alien species likely to be recently introduced in Libya: Ambigolimax valentianus (Férussac, 1822) (Limacidae) and Eleutherocaulis striatus (Simroth, 1896) (Veronicellidae) (Liberto et al., 2021). In this paper, two other alien species are reported for the first time in Libya.

\section{MATERIAL AND METHODS}

All specimens were collected by eye-sight on the ground covered under patches of grass and under rocks or flat objects. The specimens were investigated with regards to size, shell and genitalia's morphology. In order to study and illustrate genitalia, the specimens were fixed in $75 \%$ ethanol and snail bodies were isolated by crushing the shells (Polygyra) or simply by removing them from their shells (Monacha). Reproductive apparatus were extracted by means of scalpel, scissors and needles and they were studied and observed under a stereomicroscope (Leica MZ 7.5). Photographs were taken with a digital camera. Shell dimensions (number of whorls; shell diameter; shell height) and some parts of genitalia were measured (in millimeters) by a digital caliper. In the anatomical description, proximal denotes the part which is closest to the gonad and distal the part which is closest to the gonopore. The proximal female genitalia, sometimes indicated in the plates, 
are not described because they are not very informative. Taxonomical references are based on MolluscaBase (2020) and other cited papers.

Voucher specimens used for this study were stored in the following Museums and private collections: CBL: Department of Zoology collection, University of Benghazi, Libya; CL: Fabio Liberto collection, Cefalù, Italy; CS: Ignazio Sparacio collection, Palermo, Italy.

ACRONYMS. AA: atrial appendix; AG: albumen gland; BC: bursa copulatrix; DBC: duct of the bursa copulatrix; DG: digitiform gland; E: epiphallus; F: flagellum, GA: genital atrium; HD: hermaphrodite duct; O: ovotestis; OV: ovispermiduct; P: penis; PF: penial fold; PR: penial retractor muscle; V: vagina; VD: vas deferens. $\mathrm{D}$ : shell diameter; H: shell height; ex: specimen/s; sh: shell/s

\section{RESULTS}

\section{Systematics}

Phylum MOLLUSCA Cuvier, 1795

Classis PULMONATA Cuvier in Blainville, 1814 Ordo STYLOMMATOPHORA A. Schmidt, 1855

Superfamilia HELICOIDEA Rafinesque, 1815

Familia HYGROMIIDAE Tryon, 1866

Subfamilia MONACHAINAE Wenz, 1930 (1904)

Tribus MONACHAINI Wenz, 1930 (1904)

Genus Monacha Fitzinger, 1833

Subgenus Monacha Fitzinger, 1833

Monacha (Monacha) obstructa (L. Pfeiffer, 1842)

Material examined. Libya, Cyrenaica, Bodzera, Kuwayfiyah, $32^{\circ} 11^{\prime} 41^{\prime \prime} \mathrm{N} 20^{\circ} 09^{\prime} 10^{\prime \prime} \mathrm{E}, 6$ $\mathrm{m}$, leg. A. Abusneina 29.X.2018, 5 ex, 1 sh (CL 3843. CL L38 = Fig. 5); idem 1 ex (CS-5458/1); idem, 3 ex (CBL). Cyrenaica, Benghazi, Shebna, $32^{\circ} 07^{\prime} 19.6^{\prime \prime} \mathrm{N} 20^{\circ} 08^{\prime} 22.2^{\prime \prime} \mathrm{E}, 20 \mathrm{~m}$, leg. A. Abusneina 11.XI.2018, 2 ex, 1 sh (CL L92-94, Figs. 1-4). Cyrenaica, Benghazi, Alhwari, $32^{\circ} 03^{\prime} 08.3^{\prime \prime} \mathrm{N} 20^{\circ} 06^{\prime} 30.9^{\prime \prime} \mathrm{E}, 22 \mathrm{~m}$, leg. A. Abusneina 8.XI.2018, 1 ex (CL L151)

DESCRIPTION. Shell small, opaque, cream-white, characterized by a smooth protoconch of 1-1.5 whorls; teleoconch sculptured by faint and irregularly arranged riblets, the entire surface is covered by shallow pits (irregular impressions); sharp peristome, marked by a white lip which can be seen from the outside as a thick white callosity; red peristomial rim; closed umbilicus, but the last whorl forms a characteristic funnel-shaped "pseudo-umbilicus"; H: 7-8 mm, D: 11-13.5 mm. (Figs. 1-4).

Genitalia are characterized by a short $(2 \mathrm{~mm})$, conical penis; epiphallus is twice the length of the penis; slender and very long flagellum $(7-8.8 \mathrm{~mm})$, it is longer than penis and epiphallus combined; atrial appendix is very long $(6-7 \mathrm{~mm})$ reaching the length of penis and epiphallus combined or slightly longer. Its distal section is rather broad and only indistinctly delimited against the shorter, narrow proximal section; the ramified digitiform gland inserts near the distal end of the vagina (Hausdorf, 2000; Neubert \& Bariche, 2013) (Fig. 5).

DistRIBUTION AND BIOLOGY. Monacha obstructa is widespread in Turkey, Syria, Lebanon, Israel, Jordania and Egypt, also known from Saudi-Arabia, Quatar, Iraq, Iran, Pakistan probably spread by human activities.

These specimens were collected from three localities to north, east and south of Benghazi, in anthropic environments such as cultivated fields, greenhouses and gardens.

REMARKS. Monacha obstructa has been spread by human activities to countries such as Saudi Arabia and Quatar (Neubert, 1998; Al-Khayat, 2010). Also the reports of M. obstructa from Egypt seem to be due to passive introductions (Remondha, 2009; El-Sayed H. Eshra, 2013; Desoky, 2018).

Here it is reported for the first time in Libya.

Familia POLYGYRIDAE Pilsbry, 1895

Genus Polygyra Say, 1818

Polygyra cereolus (Megerle von Mühlfeldt, 1818)

Material examined. Libya, Cyrenaica, Bodzera, Kuwayfiyah, $32^{\circ} 11^{\prime} 41^{\prime \prime} \mathrm{N} 20^{\circ} 09^{\prime} 10^{\prime}$ 'E, 6 m, leg. A. Abusneina 29.X.2018, 3 ex (CL L35-37. CL L35 = Figs. 6-11). Cyrenaica, Benghazi, Jerdina, 32॰09'16.9'” 2007'16.5'E, 7 m, leg. A. Abusneina 13.XII.2018, 1 ex juven., 1 sh (CL L9596); idem, 3 ex (CBL).

DesCription. Subdiscoidal shell, with $51 / 2$ 

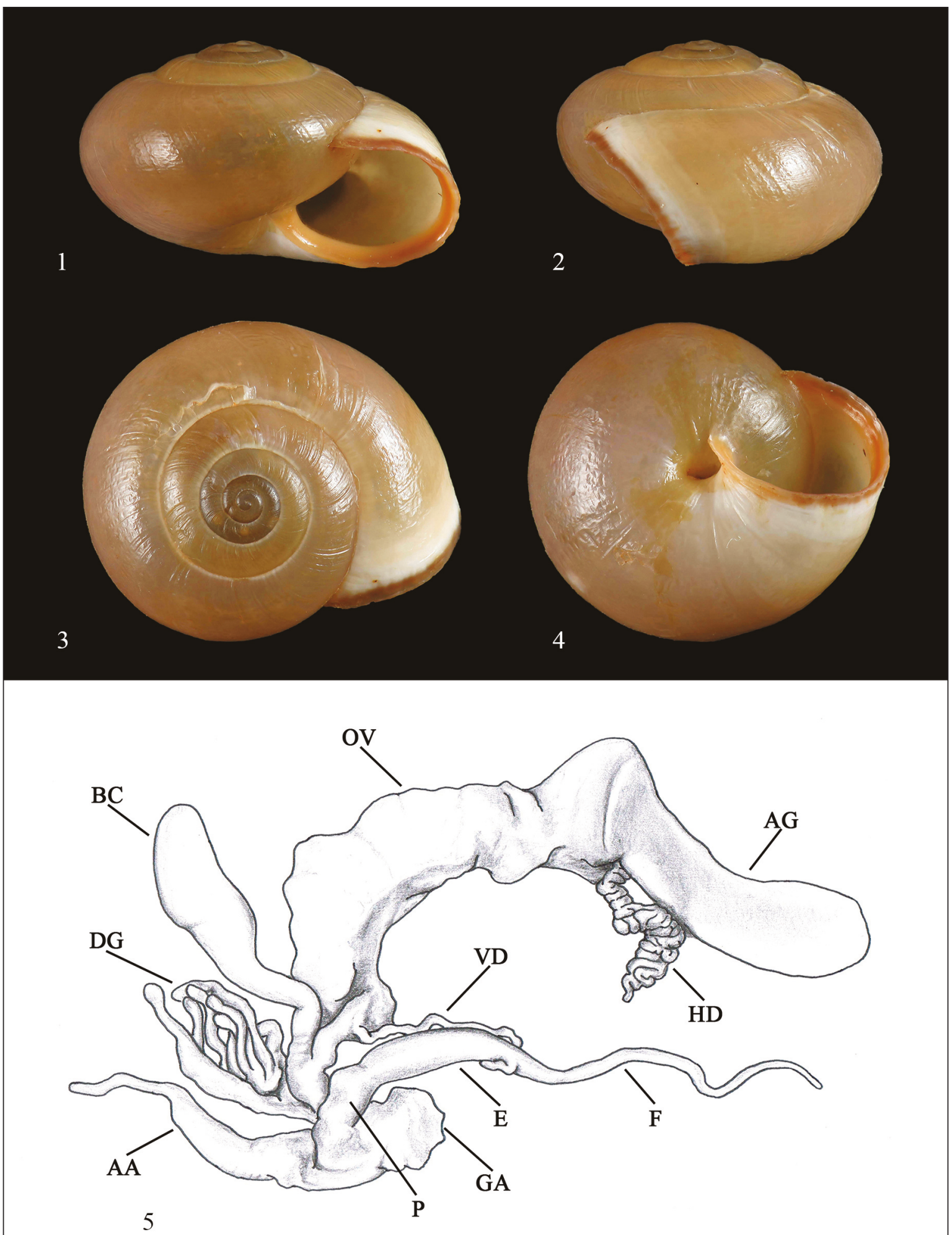

Figures 1-5. Monacha (Monacha) obstructa (L. Pfeiffer, 1842). Figs. 1-4. Libya, Benghazi, Shebna, 3207'19.6"N $20^{\circ} 08^{\prime 22} .2^{\prime \prime E}, 20$ m, leg. A. Abusneina 11.XI.2018, shell H: 7.5 mm, D: 12.5 mm. Fig. 5. Libya, Benghazi, Bodzera, Kuwayfiyah, $32^{\circ} 11^{\prime} 41^{\prime \prime} \mathrm{N} 20^{\circ} 09^{\prime} 10^{\prime \prime} \mathrm{E}, 6 \mathrm{~m}$, leg. A. Abusneina 29.X.2018, genitalia. 

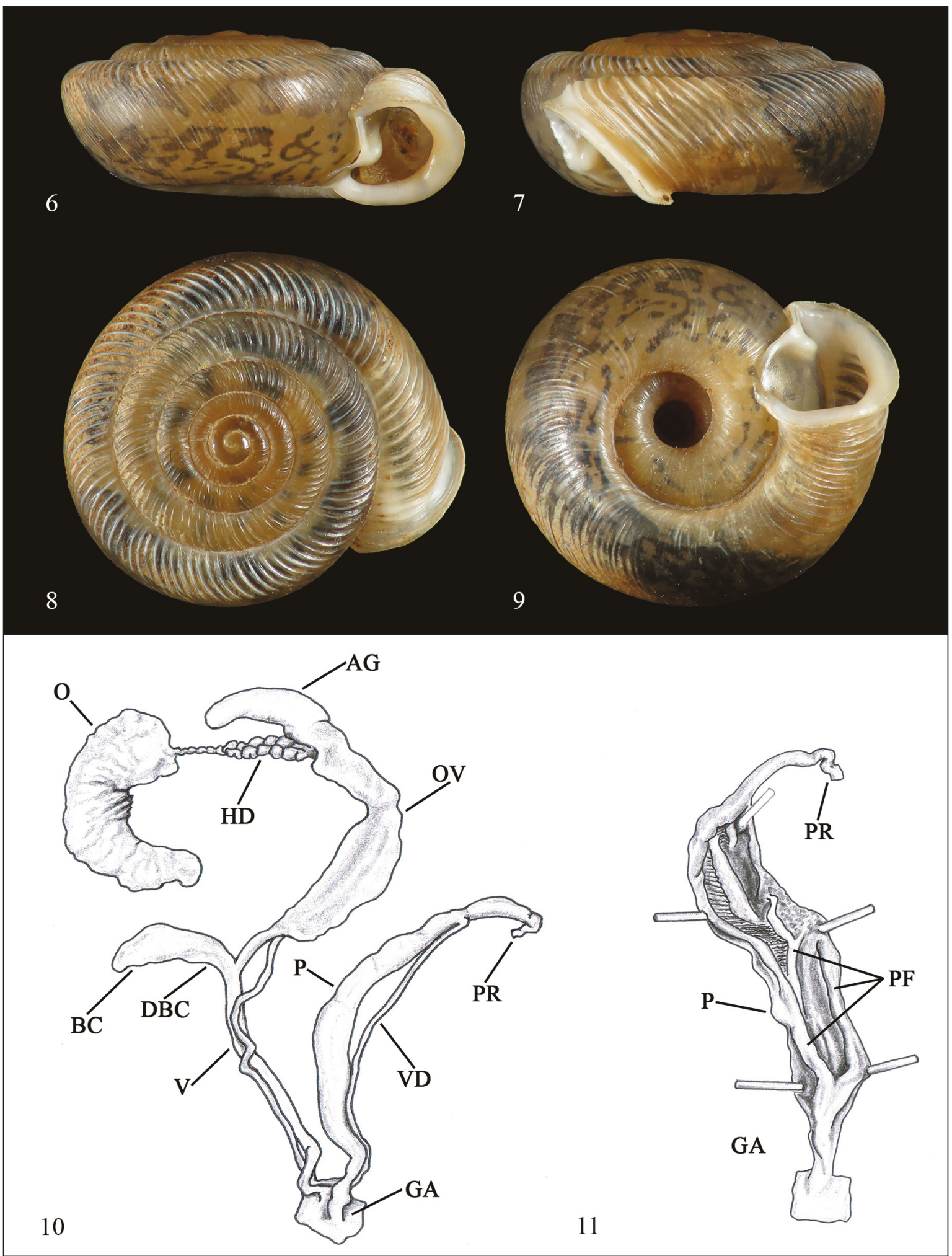

Figures 6-11. Polygyra cereolus (Megerle von Mühlfeldt, 1818), Libya, Benghazi, Bodzera, Kuwayfiyah, $32^{\circ} 11^{\prime} 41^{\prime \prime} \mathrm{N}$ 2009'10”'E, 6 m, leg. A. Abusneina 29.X.2018 (CL L35). Figs. 6-9. Shell with mollusk inside, H: 3.4 mm, D: 8.3 mm. Fig. 10. Genitalia. Fig. 11. Internal structures of the penis. 
narrowly coiled whorls, light corneous, obliquely striate; last whorl obtusely angulated at its upper edge; umbilicus broad, shallow; aperture reniform, peristome reflected with margins joined by a triangular tooth-like parietal callus. D: $7.5-8 \mathrm{~mm}$, H: 3.5 mm (Figs. 6-9).

Genitalia are characterized by a long and very slender vagina, relatively short free oviduct; oval bursa copulatrix with a very short duct of the bursa copulatrix; very long penis $(6-7 \mathrm{~mm})$ with few internally longitudinal folds. (Figs. 10-11).

Distribution AND Biology. Polygyra cereolus is native to South Carolina and Florida westward to Texas (USA) (Pilsbry, 1940) but it has been introduced by human activities in many other countries. It was reported chronologically in Saudi Arabia (Neubert, 1995), Hawaii (Cowie, 1996), United Arab Emirates (Feulner et al., 2005), Qatar (Al-Khayat, 2010), Mexico (Thompson, 2011), Spain (Navarro-Barrachina et al., 2012; QuinoneroSalgado \& Soriano, 2015), Caribbean region (Charles, 2014), Italy (Baraggia \& Gariani, 2018), Egypt (Ali \& Robinson, 2020).

REMARKs. Polygyra cereolus is the only species in the genus to have been reported as an invasive species. One of the main vectors for the spread and introduction of $P$. cereolus appears to be the trade and transport of ornamental shrubs and grass sod.

This is the first finding of $P$. cereolus from Libia, confirming the increasing geographical expansion of this invasive species.

\section{CONCLUSIONS}

Liberto et al. (2021) reported the presence in Libya of the alien species Eleutherocaulis striatus and Ambigolimax valentianus. Here we add two other non-native species $M$. obstructa and $P$. cereolus. These four species come from different biogeographical units: L. striatus is native to central Africa; A. valentianus described for the surroundings of Valencia and is probably native to Spain and north-west Africa; M. obstructa has its range of origin in the Middle East and finally P. cereolus originates from the southeastern United States.

Their introduction to Libya was probably through imported soil, natural fertilizers, and / or other plant products.
The rate of introduction of alien species, such as snails and slugs, is increasing in all regions. Quarantine measures are therefore necessary to prevent the introduction of species that are potentially harmful to agricultural crops as well as to natural environments, thus preventing expensive eradication actions that are often unsuccessful.

\section{REFERENCES}

Ali R.F. \& Robinson D. G., 2020. Four records of new to Egypt gastropod species including the first reported tropical leatherleaf slug Laevicaulis alte (D'A. De Férussac, 1822) (Pulmonata: Veronicellidae). Zoology and Ecology, 30: 138-156.

https://doi.org/10.35513/21658005.2020.2.8

Al-Khayat J.A., 2010. First record of five terrestrial snails in the State of Qatar. Turkish Journal of Zoology, 34: 539-545.

https://doi.org/10.3906/zoo-0807-26

Baraggia A. \& Gariani G., 2018. Prima segnalazione di Polygyra cereolus (Muhlfeld, 1816) (Gastropoda: Pulmonata: Polygyridae) per l'Italia. Alleryana, 36: 91-92.

Charles L., 2014. Signalement de Polygyra cereolus (Megerle von Mühlfeldt, 1816) (Mollusca: Gastropoda: Polygyridae) à la Guadeloupe (PetitesAntilles). MalaCo, 10: 5-6.

Cowie R. H., 1996. New records of introduced land and freshwater snails in the Hawaiian Islands. Records of the Hawaii Biological Survey for 1995, part 2, 46: 25-27.

Desoky A.S.S., 2018. Identification of terrestrial gastropods species in Sohag Governorate, Egypt. Archives of Agriculture and Environmental Science, 3: $45-48$. https://doi.org/10.26832/24566632.2018.030105

El-Sayed H. Eshra, 2013. Survey and distribution of terrestrial snails in fruit orchards and ornamental plants at Alexandria and El-Beheira Governorates, Egypt. Alexandria Sciece exchange Journal, 34: 242-248.

Feulner G., Neubert E. \& Green S.A., 2005. Land snails, pp. 222-226. In: P. Hellyer and S. Aspinall (Eds.), The Emirates. A natural history. Trident Press Limited: 222-226.

Hausdorf B., 2000. The genus Monacha in Turkey. Archiv für Molluskenkunde, 128: 61-151.

Liberto F., Abusneina A. \& Sparacio I., 2021. New data on slugs and semy-slugs from Cyrenaika (northeastern Libya) (Parmacellidae, Limacidae, Agliolimacidae, Veronicellidae). Biodiversity Journal, 12: 325-334. https://doi.org/10.31396/Biodiv.Jour.2021.12.2.325.334 
MolluscaBase eds., 2020. MolluscaBase. Accessed at www.molluscabase.org on 2020.11.14

Navarro-Barrachina S., López Alabau A., Pérez Ferrer A., Jarillo R.R. \& Salgado Q., 2012. Sobre la presencia de Polygyra cereolus (Mühlfeldt, 1816) (Gastropoda: Polygyridae) en Espana. Spirula, 4: 169-170.

Neubert E., 1995. Two species of land snails in Saudi Arabia. Malacological Review, 28: 125-126.

Neubert E., 1998. Annotated checklist of the terrestrial and freshwater molluscs of the Arabian Peninsula with descriptions of new species. Fauna of Arabia, 17: 333-461.

Neubert E. \& Bariche M., 2013. On the Monacha species of Lebanon (Gastropoda, Hygromiidae). Zookeys, 311: $1-18$

http://dx.doi.org/10.3897/zookeys.311.5408
Pilsbry H. A., 1940. Land Mollusca of North American (North of Mexico). The Academy of Natural Sciences, Philadelphia, Monograph 3, vol. 1 (2): 575-994.

Quiñonero Salgado S. \& Soriano J. L., 2015. Nuevas citas de Polygyra cereolus (Mühlfeldt, 1816) (Gastropoda: Polygyridae) en Cataluña. Spirula, 5: 199-200.

http://dx.doi.org/10.33800/nc.vil6.234

Remondah R. R., 2009. Biological and ecological studies on land snails ata Assiut, Egypt. Thesis - Faculty of Science, Assiut University, 164 pp.

Thompson F.G., 2011. An Annotated Checklist and Bibliography of the Land and Freshwater Snails of Mexico and Central America. Bulletin of the Florida Museum of Natural History, 50: 1-299. 